\title{
Optimización de la recuperación de Pseudomonas syringae pv. tabaci por la modificación de dos medios de cultivo
}

\author{
Marusia Stefanova1, Pedro Ivo A.L. Sala ${ }^{2}$, Joanice P.S. Damasceno² \& Abi S.A. Marques ${ }^{2}$ \\ ${ }^{1}$ Instituto de Investigaciones de Sanidad Vegetal - INISAV, Ciudad de La Habana, Cuba; ${ }^{2}$ Laboratório de Quarentena Vegetal, \\ Embrapa Recursos Genéticos e Biotecnologia, 70.770-917, Brasília, DF, Brasil
}

Autor para correspondência: Abi S.A. Marques, e-mail: amarques@cenargen.embrapa.br

\begin{abstract}
RESUMEN
Los medios de cultivo, selectivos y semiselectivos, favorecen al aislamiento de las bacterias fitopatógenas, mediante la supresión de microorganismos no deseados. Para optimizar la recuperación de Pseudomonas syringae pv. tabaci, a partir de semillas de tabaco se emplearon dos medios de cultivo: KB (medio B de King et al.) y MSP ("modified sucrose peptone", medio de Mohan y Schaad), a los que fueron adicionados los antibióticos ciclohexamida y cefalexina. La eficacia de los medios se comprobó mediante siembra de una suspensión bacteriana y de semillas de tabaco infectadas, utilizando como testigo el medio KB sin drogas. Ninguno de los medios estudiados suprimió el crecimiento de la bacteria, mientras que los contaminantes presentes en las muestras, fueron reducidos en los medios con antibióticos dos o más veces, en comparación con el testigo. Las colonias de P. syringae pv. tabaci en el medio MSP modificado pudieron ser evaluadas a las 48 horas y mostraron una morfología fácilmente distinguible de las colonias contaminantes.

Palabras clave: Nicotiana tabacum, fuego salvage, patología de semillas, métodos de detección.

ABSTRACT

Recovering optimization of Pseudomonas syringae pv. tabaci by use of two modified semiselective medium

Selective or semiselective medium increases the isolation of plant pathogenic bacteria, supressing undesirable microorganisms. Aiming optimize the isolation of Pseudomonas syringae pv. tabaci from tobacco seeds, two culture media were used: KB (King et al.'s medium B) and MSP ("modified sucrose peptone", Mohan \& Schaad's medium), amended with cyclohexamida and cephalexin. The efficacy of both media was evaluated by plating bacterial suspension and seed extracts. KB without antibiotics was used as control. Any media suppressed bacterial growth, but eliminate contaminants, as high as two times when compared to the control. Bacterial colonies in modified MSP were evaluated $48 \mathrm{~h}$ after plating, showing a highly distinct aspect form those of contaminants.
\end{abstract}

Keywords: Nicotiana tabacum, wild fire, seed pathology, detection methods.

Las bacterias fitopatógenas del género Pseudomonas, grupo syringae, causantes de manchas, tizón y cancrosis, son transmitidas por las semillas y pueden permanecer asociadas a las plantas como epifitas foliares o en la rizosfera. Los estudios epidemiológicos y de diagnóstico requieren el aislamiento de la bacteria para la realización de la prueba de patogenicidad y la caracterización morfológica, fisiológica y genética del patógeno (Braun-Kendrick \& Sands, 2001).

En este sentido, los medios de cultivo, selectivos y semiselectivos, han resultado muy útiles porque contienen diversas drogas que suprimen los microorganismos semejantes no deseados. Braun-Kendrick \& Sands (2001) citan al medio de cultivo BCBRVB (medio B de King et al., con suplementos de cicloexamida, bacitracin, rifamicina, vancomicina $\mathrm{y}$ benomil) para el aislamiento de patovares de $P$. syringae van Hall, a partir de insectos y residuos de plantas, con una alta sensibilidad. Leben (1972) propuso el medio de cultivo M-71 como semiselectivo para $P$. savastanoi pv. glycinea (Coerper) Gardan et al., donde la bacteria muestra colonias con morfología característica. Otro medio con una alta selectividad para este patógeno fue informado por Fieldhouse \& Sasser (1982). Por otra parte Mohan y Schaad (1987) acondicionaron el medio MSP con la adición de varios compuestos antimicrobianos y bromotimol azul, para el aislamiento de Pseudomonas syringae pv. syringae van Hall y P. savastanoi pv. phaseolicola (Burk.) Gardan et al., con resultados satisfactorios para el aislamiento de las dos especies.

El patógeno $P$. syringae pv. tabaci (Wolf \& Foster) Young et al. 1978, agente causal del fuego salvaje en el cultivo del tabaco, se transmite por las semillas cuya contaminación ocurre a través de las cápsulas lesionadas (Agrios, 2005; Gao \& Gao, 1997). La diseminación por esta importante vía ha trasladado la enfermedad en la mayoría de los países que cultivan el tabaco (Shoemaker, 1990). En la literatura especializada no se encontró referencia sobre un medio de cultivo con selectividad para el aislamiento de $P$. syringae pv. tabaci. El presente trabajo tuvo como objetivo utilizar, con algunas modificaciones, dos de los medios de cultivo citados anteriormente [MSP, Mohan \& Schaad (1987) y KB, King et al. (1954)] para optimizar el aislamiento de $P$. syringae pv. tabaci principalmente a partir de las semillas. 
Se seleccionó el medio MSP (Mohan \& Schaad, 1987), con la siguiente composición: sacarosa (20 g/L), peptona $(5 \mathrm{~g} / \mathrm{L}), \mathrm{K}_{2} \mathrm{HPO}_{4}(0,5 \mathrm{~g} / \mathrm{L}), \mathrm{MgSO}_{4} \cdot 7 \mathrm{H}_{2} \mathrm{O}(25,0$ $\mathrm{mg} / \mathrm{L})$, agar $(20 \mathrm{~g} / \mathrm{L})$, cicloexamida $(200 \mathrm{mg} / \mathrm{L})$, cefalexina $(80 \mathrm{mg} / \mathrm{L})$, vancomicina $(10 \mathrm{mg} / \mathrm{L})$ y bromotimol azul $(15$ $\mathrm{mg} / \mathrm{L}$ ). De los tres antibióticos que lo integran se retiró el vancomicina, quedando como suplementos los primeros dos (ciclohexamida y cefalexina) y el bromotimol azul, sin alterar las concentraciones primarias. El medio será denominado a partir de este punto MSP-M (MSP Modificado).

Para conocer el crecimiento de P. syringae pv. tabaci en el medio, se preparó una suspensión en el tampón PBS estéril de la cepa Emb.D 135 (IBSBF 766), cultivada por $24 \mathrm{~h}$ en el medio KB [King et al. (1954), con la siguiente composición: proteosa peptona $(20 \mathrm{~g} / \mathrm{L}), \mathrm{K}_{2} \mathrm{HPO}_{4}(1,5 \mathrm{~g} / \mathrm{L})$, $\mathrm{MgSO}_{4} 7 \mathrm{H}_{2} \mathrm{O}(1,5 \mathrm{~g} / \mathrm{L})$, glicerol $(15,0 \mathrm{ml} / \mathrm{L})$, agar $\left.(15 \mathrm{~g} / \mathrm{L})\right] \mathrm{y}$ se realizaron diluciones decimales seriadas hasta $10^{-6} \mathrm{ufc} / \mathrm{mL}$. La siembra se efectuó esparciendo $100 \mu \mathrm{L}$ de suspensión por placa, con tres replicas y se incluyó como medio testigo el KB, sin droga alguna. Las placas fueron observadas durante 24$72 \mathrm{~h}$, se realizaron conteos de las colonias y se describió su morfología. También se calcularon las poblaciones bacterianas presentes en las variantes y en el medio de cultivo testigo, en tres repeticiones.

Semillas de tabaco de la variedad TNN fueron inoculadas con suspensión concentrada a más de $10^{9} \mathrm{ufc} /$ mL, preparada a partir de la cepa Emb.D 135, con 24 h de crecimiento, mediante inmersión en la suspensión durante tres horas. Posteriormente, se secaron a temperatura ambiente y se conservaron a $12^{\circ} \mathrm{C}$. De las semillas inoculadas se tomaron muestras que fueron depositadas en tampón PBS estéril con una proporción semillas-buffer de 1 por 2 , seguido de una extracción de la bacteria por lavado de las semillas en agitadora a $100 \mathrm{rpm}$ durante tres horas o mediante remojo a $5^{\circ} \mathrm{C}$ por una noche. Se efectuaron diluciones decimales seriadas y siembra, con tres replicas, esparciendo $100 \mu \mathrm{L}$ por placa de los medios de cultivo ensayados y en el medio testigo. A las 48$72 \mathrm{~h}$ se contabilizaron las colonias del patógeno y las colonias contaminantes recobradas.

Siendo el medio de cultivo KB muy utilizado en el diagnóstico y el estudio de las especies del género Pseudomonas, se efectuó un ensayo preliminar donde el medio fue suplementado con ciclohexamida y cefalexina en las mismas dosis que en el medio MSP modificado (MSP-M). En las placas con medio de cultivo MSP-M, a las $48 \mathrm{~h}$ las colonias de $P$. syringae pv. tabaci pueden definirse como elevadas, brillantes, con bordes enteros de color amarillo claro, que, a las $72 \mathrm{~h}$ se torna más oscuro casi anaranjado, con cambio de color del medio entorno de las colonias, de verde a amarillo (Figura 1). La recuperación de $2,3 \times 10^{7} \mathrm{ufc} / \mathrm{mL}$ en medio de cultivo MSP-M a partir de la suspensión bacteriana, se situó en el mismo rango de sensibilidad que el registrado en el medio de cultivo testigo $\left(2,5 \times 10^{7} \mathrm{ufc} / \mathrm{mL}\right)$, lo cual demuestra que las drogas utilizadas para mejorar la selectividad no reducen el crecimiento de la bacteria objeto de estudio.

En los ensayos realizados con semillas de tabaco se pudo constatar que el medio de cultivo MSP-M reduce sustancialmente, en comparación con el testigo, la presencia de contaminantes bacterianos (Tabla 1), cuya morfología además, es diferente de la morfología de las colonias de

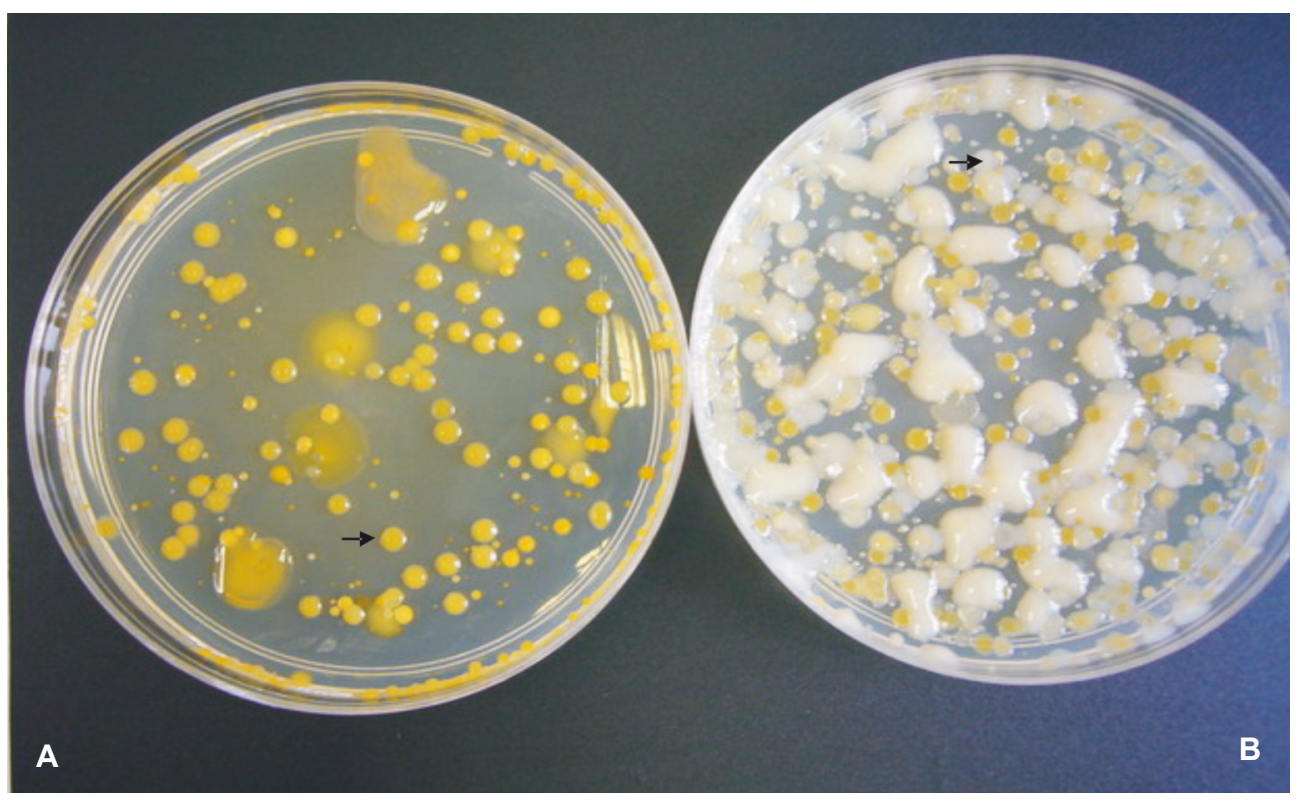

FIGURA 1 - Aspecto de las placas de Petri con los medios de cultivos evaluados para la supresión de contaminantes en el aislamiento de Pseudomonas syringae pv. tabaci: A. Medio de cultivo semi-seletivo MSP (Mohan \& Schaad, 1987) modificado; B. medio de cultivo KB (King et al., 1954) normalmente utilizado para el aislamiento de la bacteria. Las flechas indican las colonias de P. syr. tabaci. 
TABLA 1 - Supresión de contaminantes en el medio semi selectivo MSP-M ("modified sucrose peptone"-Modificado) a partir de muestras de semillas de tabaco contaminadas ${ }^{2}$ con Pseudomonas syringae pv. tabaci en comparación con el medio KB (medio B de $\mathrm{King}^{3}$ )

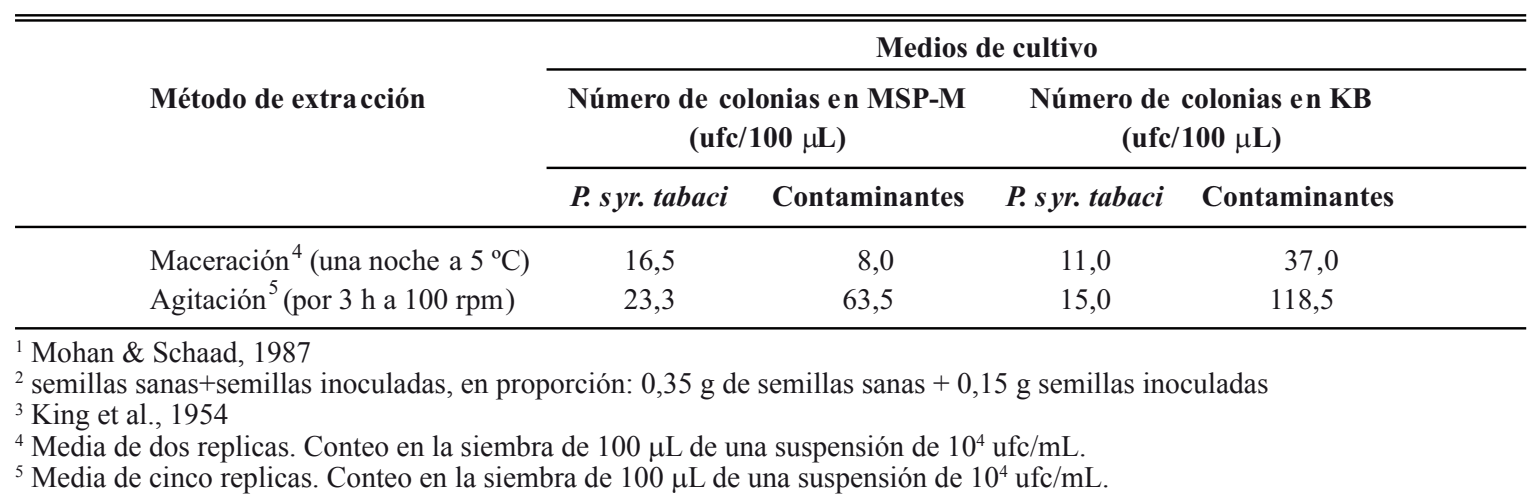

P. syringae pv. tabaci. Hubo crecimiento de colonias de hongos contaminantes en el testigo, que fueron suprimidas en MSP-M. Aunque la selectividad del medio de cultivo $\mathrm{KB}$ suplementado con la ciclohexamida y cefalexina fue inferior a la del medio MSP-M, las placas mostraron mucho menos colonias contaminantes que el testigo (placas KB sin drogas) y el mismo puede ser utilizado para facilitar el aislamiento de $P$. syringae pv. tabaci.

La sanidad de las semillas de tabaco reviste una gran importancia para el intercambio internacional entre los países productores (CORESTA, 2005). Las semillas contaminadas con la bacteria constituyen la fuente primaria de infección, que en condiciones favorables pueden causar grandes pérdidas en el cultivo, siendo el uso de semillas sanas la medida más importante para el manejo de la enfermedad. El medio MSP-M puede complementar el método de extracción y recuperación de $P$. syringae pv. tabaci (Stefanova et al., 2008), con el incremento de la selectividad en el aislamiento, similar a la que fue observada para Curtobacterium flaccumfaciens pv. flaccumfaciens (Hedges) Collins \& Jones (Maringoni et al., 2006). Con el mismo propósito también puede ser empleado el medio KB suplementado con ciclohexamida y cefalexina.

El aislamiento de $P$. syringae pv. tabaci a partir de síntomas iniciales no es un problema, pero si se trata de hojas de tabaco con estado avanzado de enfermedad, donde más de un microorganismo puede estar presente, es difícil. Aunque los dos medios de cultivo modificados no fueron ensayados con plantas de tabaco afectadas, también se puede esperar en este caso, un efecto selectivo favorable debido a la acción de las drogas utilizadas como suplemento, ya que las dosis finales de ellas no afectan la recuperación de la bacteria fitopatógena. Los medios de cultivo modificados, ensayados con un lote de semillas contaminadas artificialmente, deberán ser validados con lotes de semillas naturalmente contaminadas, procedentes de campos con diferentes índices de manifestación de los síntomas, para que sea avalada la eficacia de los mismos.
Ambos medios de cultivo pueden formar parte de un sistema de diagnóstico para $P$. syringae pv. tabaci, donde son integradas técnicas clásicas y de alta sensibilidad para incrementar la eficacia en el diagnóstico de la bacteria.

\section{AGRADECIMIENTOS}

La primera autora agradece al Conselho Nacional de Desenvolvimento Científico e Tecnológico - CNPq por el apoyo para la estadía en Brasil (Proc. 68.0000/2005-4 e 48.0001/2005-7).

\section{REFERENCIAS BIBLIOGRÁFICAS}

Agrios GN (2005) Plant Pathology. $5^{\text {th }}$ Ed. New York NY. Academic Press.

Braun-Kiewnick A, Sands DC (2001) Gram-Negative Bacteria - Pseudomonas. In: Schaad NW, Jones JB, Chun W (Eds.) Laboratory guide for identification of plant pathogenic bacteria. Saint Paul MN. APS Press. pp. 84-120.

Coresta (2005) Tobacco seed integrity task force. Final report. Disponível em: http://www.coresta.org/reports/seed-integrity-TFmay. 05 p. Acesso em: 4/fev/2008.

Fieldhouse DJ, Sasser M (1982) A medium highly selective for Pseudomonas syringae pv. glycinea. Phytopathology (Suppl.)72: S706.

Gao J, Gao J (1997) Study on occurrence of tobacco wildfire disease. Journal of Jilin Agricultural University 19:8-15.

King EO, Ward WK, Raney DE (1954) Two simple media for the demonstration of pyocyanin and fluorescein. Journal of Laboratory and Clinical Medicine 44:301-307.

Leben C (1972) The development of a selective medium for Pseudomonas glycinea. Phytopathology 62:674-676.

Maringoni AC, Camara RC, Souza VL (2006) Semi-selective culture medium for Curtobacterium flaccumfaciens pv. 
Optimización del recobrado de Pseudomonas syringae pv. tabaci...

flaccumfaciens isolation from bean seeds. Seed Science and Technology 34:117-124.

Mohan SK, Schaad NW (1987) Semiselective agar media for isolating Pseudomonas syringae pv. syringae and Pseudomonas syringae pv. phaseolicola from bean seed. Phytopathology 77:1390-1395.
Shoemaker PB (1991) Foliar diseases caused by bacteria In: Shew HD, Lucas GB (Eds.) Compendium of tobacco diseases. Saint Paul MN. APS Press. pp. 30-33.

Stefanova M, Oliveira GHN, Viana FC (2008) Recobrado de Pseudomonas syringae pv. tabaci a partir de semillas de tabaco infectadas. Fitosanidad 12:21-25.

Recebido 18 Agosto 2008 - Acceptado 29 Maio 2009 - TPP 8102 Editor Associado: Valmir Duarte 